\title{
Involvement of Endoplasmic Reticulum Stress Response in Orofacial Inflammatory Pain
}

\author{
Eun Sun Yang ${ }^{1}$, Jin Young Bae ${ }^{1}$, Tae Heon Kim ${ }^{1}$, \\ Yun Sook Kim ${ }^{1}$, Kyoungho Suk ${ }^{2}$ and Yong Chul Bae ${ }^{1 *}$ \\ ${ }^{1}$ Department of Anatomy and Neurobiology, School of Dentistry, Kyungpook National University, Daegu 700-412, \\ ${ }^{2}$ Department of Pharmacology, Brain Science \& Engineering Institute, BK21 Plus KNU Biomedical Convergence Program, \\ Kyungpook National University School of Medicine, Daegu 700-422, Korea
}

Endoplasmic reticulum (ER) stress is involved in many neurological diseases and inflammatory responses. Inflammatory mediators induce neuronal damage and trigger the neuropathic or inflammatory pain. But there is very little data on the role of the ER stress response in pain mechanisms. In this study, we explored whether the ER stress response is involved in orofacial inflammatory pain by using a complete Freund's adjuvant (CFA)-injected rat model. The thermal pain hypersensitivity increased significantly after CFA injection. We found that the protein and mRNA levels of ER stress response genes, GRP78/Bip and p-eIF2a, increased significantly in trigeminal ganglion (TG) of CFA-injected rats compared to control animals. In immunofluorescence analysis, a significant increase of GRP78 and p-eIF2a immunopositive neurons was observed in CFA-injected TG compared to control TG. When we administered an ER stress modulator, salubrinal, CFA-induced thermal pain hypersensitivity was temporally reduced. Thus, our study suggests that ER stress responses in TG neurons contribute to CFA-induced inflammatory pain, and may comprise an important molecular mechanism underlying the orofacial inflammatory pain pathway.

Key words: ER stress, trigeminal ganglion, inflammatory pain, orofacial pain

\section{INTRODUCTION}

The endoplasmic reticulum (ER) is an important cellular organelle involved in $\mathrm{Ca}^{2+}$ homeostasis, post-translational modification, and cell death signaling [1,2]. Physiological or pathological conditions, such as glucose deprivation, disturbance of $\mathrm{Ca}^{2+}$ homeostasis, accumulation of abnormally folded protein in the lumen of ER, and exposure to oxidative

Received September 17,2014, Revised October 22, 2014 ,

Accepted October 22, 2014

* To whom correspondence should be addressed. TEL: 82-53-660-6860, FAX: 82-53-426-7731 e-mail:ycbae@knu.ac.kr stress cause ER stress, activating the ER stress response (UPR, unfolded protein responses) within the cells $[3,4]$. The ER stress response is a conserved reaction in all mammalian species, protecting the cells from injuries. During the ER stress response, the following reactions occur: 1) translational attenuation to prevent accumulation of abnormal proteins, 2) induction of ER chaperones to increase protein folding activity, 3) elimination of misfolded proteins by protein degradation system, 4) initiation of the ER stress-induced cell death by the excessive stresses $[1,5]$. The activation of ER stress response is also implicated in the numerous diseases including ischemia reperfusion, neurodegenerative diseases, multiple sclerosis and diabetes [3].

ER stress is closely associated with inflammatory responses. Inflammation is the first biological response to toxic stimuli and 
tissue injury [6,7]. Inflammatory response occurs with homeostatic metabolic process including ER stress. The cross-talk between ER stress and inflammatory response is not unidirectional, so they can affect each other [7]. The signaling pathway between ER stress and inflammatory response is connected through several mechanisms, including the reactive oxygen species (ROS), $\mathrm{Ca}^{2+}$ store, nuclear factor- $\kappa \mathrm{B}(\mathrm{NF}-\kappa \mathrm{B})$, and mitogen-activated protein kinase (MAPK) [8,9]. Recent studies suggested that ER stress response might be the key reaction in many inflammatory diseases and neuroinflammation [10,11].

Inflammation of peripheral nerves activates numerous nociceptors and induces pain hypersensitivity [12]. Many proalgesic mediators such as cytokines, neurotrophic factors, prostaglandins, and bradykinin increase during the inflammatory response $[13,14]$. Inhibition of these mediators reduces the hyperalgesia in inflammatory pain models, indicating their importance in the progression of inflammatory pain [15]. Inflammation itself indicates that the tissue is damaged and not in the normal state. The proinflammatory substances released from the inflammation site can cause damage to the neuronal cells, and may trigger the ER stress responses.

In spite of much knowledge about the inflammatory response, activation of the ER stress and pain, little is known about the relationship between the ER stress response and pain mechanisms in sensory nervous systems. Recently, it has been reported that nerve injury induces ER stress response in the dorsal root ganglion (DRG) of neuropathic pain model, and ER stress response occurs with cell type-dependent response in spinal cord injury model [16-18]. However, the role of ER stress response in the trigeminal ganglion (TG) of peripheral inflammatory pain model is poorly understood. TG is a key location of primary afferent neurons for sensing orofacial pain conditions such as dental pain and temporomandibular disorders [19]. To develop effective therapy for orofacial pain, research into the molecular mechanisms of ectopic pain hypersensitivity induced by local inflammation in the orofacial region is important. In this study, we utilized a rodent model of orofacial inflammatory pain where complete Freund's adjuvant (CFA) is directly injected into rat face, and investigated the possible involvement of TG ER stress response in pain hypersensitivity evoked by CFA-mediated peripheral inflammation.

\section{MATERIALS AND METHODS}

\section{Animals and drug treatment}

6-to 8-week old male Sprague-Dawley rats (200 250 g) were used in this study. All animal procedures were performed according to the National Institutes of Health guidelines and approved by the Kyungpook National University Intramural Animal Care and Use Committee. The animals were cared for at controlled temperature and humidity with free access to food and water. All experiments were performed to minimize the number of animals used and their suffering. CFA (Sigma) was mixed with saline (1:1) and $60 \mu$ of CFA solution was injected into the right vibrissal pad, and the TGs were extracted 5 days after CFA injection. The control groups were injected with the same volume of saline in the vibrissal pad. For injection of salubrinal into TG, we performed the cannula implantation using the stereotaxic apparatus. The skull was exposed, and a bur hole was drilled above the location of the TG. A guide cannula was anchored onto the skull using three stainless steel screws and dental cement. At least 5 days were allowed for recovery from surgery before drug injection into the TG [20].

\section{Western blot analysis}

Rats were deeply anesthetized with sodium pentobarbital (80 $\mathrm{mg} / \mathrm{kg}$, i.p.) and perfused with $100 \mathrm{ml}$ of heparinized normal saline. The rat whole TGs were removed and homogenized in extraction buffer containing $20 \mathrm{mM}$ Tris- $\mathrm{HCl}$ ( $\mathrm{pH}$ 7.4), 5 mM EDTA, $140 \mathrm{mM} \mathrm{NaCl}, 1 \%$ Triton X-100, $1 \mathrm{mM}$ sodium orthovanadate $\left(\mathrm{Na}_{3} \mathrm{VO}_{4}\right), 1 \mathrm{mM}$ phenylmethylsulfonyl fluoride (PMSF), $10 \mathrm{mM}$ sodium fluoride $(\mathrm{NaF})$ and $1 \mu \mathrm{g} / \mathrm{ml}$ aprotinin at $4^{\circ} \mathrm{C}$. The extracts were centrifuged at $12,000 \times \mathrm{g}$ for $20 \mathrm{~min}$ at $4^{\circ} \mathrm{C}$. The protein content in the supernatant was measured using a Bio-Rad Protein Assay kit (Bio-Rad, Hercules, CA). The protein lysates were denatured at $95^{\circ} \mathrm{C}$ for 5 min after mixing with SDS-loading buffer (5X), applied on an SDS polyacrylamide gel for electrophoresis. Proteins were transferred to Immobilon-P membranes (Millipore Corporation, Bedford, MA). The membrane was soaked in blocking solution (1X TBS, 5\% nonfat milk, $0.02 \%$ sodium azide) for $2 \mathrm{~h}$ and incubated overnight at $4^{\circ} \mathrm{C}$ with the primary antibodies [mouse monoclonal antibody against GRP78 (\#BD610979, 1:1,000, BD BioSciences) and rabbit monoclonal antibody to p-eIF2a (\#3597, 1:1,000, Cell Signaling)]. The membrane was washed with TBS (1X) and incubated with HRP-conjugated secondary antibodies [goat anti-rabbit IgG (\#sc2004, 1:2,000, Santa Cruz Biotechnology) and goat anti-mouse IgG (\#sc2005, 1:2,000, Santa Cruz Biotechnology)] for $1 \mathrm{~h}$ at room temperature. Detection of specific proteins was carried out with an ECL Western blotting kit (Millipore Corporation, Bedford, MA) according to the manufacturer's instructions and exposed on autoradiography film (Agfa).

\section{RT-PCR analysis}

For reverse-transcription PCR (RT-PCR) analysis, rats were 
deeply anesthetized with sodium pentobarbital ( $80 \mathrm{mg} / \mathrm{kg}$, i.p.) and perfused with $100 \mathrm{ml}$ of heparinized normal saline. The rat whole TGs were removed and total RNA was extracted using Trizol reagent (Invitrogen), according to the manufacturer's instructions. In brief, single-strand cDNA was synthesized from $1 \mu \mathrm{g}$ of total RNA using M-MLV reverse transcriptase (GibcoBRL, Gaithersburg, MD). The cDNA for GRP78 and ATF4 was amplified by PCR with specific primers. The sequences of the primers for GRP78 were 5' -CTG GGT ACA TTT GAT CTG ACT GG-3' (sense), 5' -GCA TCC TGG TGG CTT TCC AGC CAT TC-3' (antisense) and ATF4 were 5'-GTG GCC AAG CAC TTC AAA CCT CAT-3' (sense), 5' -CAT GTG TCA TCC AAC GTG GCC AAA- $3^{\prime}$ (antisense). Conditions for PCR reaction were $1 \times\left(95^{\circ} \mathrm{C}, 5 \mathrm{~min}\right) ; 27 \times\left(95^{\circ} \mathrm{C}, 30 \mathrm{sec} ; 56^{\circ} \mathrm{C}, 30 \mathrm{sec}\right.$; and $72^{\circ} \mathrm{C}, 45$ sec); and $1 \times\left(72^{\circ} \mathrm{C}, 5 \mathrm{~min}\right)$. The relative concentration of GRP78 and ATF4 in the samples was normalized with the expression levels of GAPDH. PCR products were analyzed by agarose gel electrophoresis and visualized by ethidium bromide.

\section{Immunohistochemistry analysis}

For immunofluorescence analysis, rats were deeply anesthetized with sodium pentobarbital ( $80 \mathrm{mg} / \mathrm{kg}$, i.p.) and transcardially perfused them with $100 \mathrm{ml}$ of heparinized normal saline, followed by $500 \mathrm{ml}$ freshly prepared fixative containing $4 \%$ (w/ v) paraformaldehyde in $0.1 \mathrm{M}$ phosphate buffer ( $\mathrm{pH}$ 7.4). The TG sections were permeabilized with 50\% ethanol for $30 \mathrm{~min}$, blocked with $10 \%$ normal donkey serum (NDS) for $30 \mathrm{~min}$, and incubated overnight in the primary antibodies [goat polyclonal antibody to GRP78 (sc1050, 1:200, Santa Cruz Biothechnology), rabbit monoclonal antibody to p-eIF2a (\#3597, 1:500, Cell Signaling) and the neuronal marker, microtubule associated protein (MAP2; \#ab11267, 1:1,000, Abcam)]. TG sections were washed with 0.01 M phosphate buffered saline (PBS, pH 7.4) and incubated with $2 \%$ NDS for $30 \mathrm{~min}$, and incubated with secondary antibodies [Cy3-conjugated-donkey anti-goat antibody, Cy3-conjugateddonkey anti-rabbit antibody and FITC-conjugated-donkey antimouse antibody (1:200 in PBS; Jackson Immunoresearch)] for 3 h. Finally, sections were rinsed with PBS, mounted on slides, and coverslipped with Vectashield (Vector, Burlingame, CA) solution. Microscopic observation was performed with an Exi digital camera (Q-Imaging Inc, Surrey, CA) attached to a Zeiss Axioplan 2 conventional fluorescence microscope (Carl Zeiss Inc, Jena, Germany).

\section{Cell size distribution analysis}

In immunostaining, we analyzed approximately 500 neurons that contained visible nuclei in sections for each TG. Cell size distribution of p-eIF $2 \alpha$-immunopositive neurons and proportion of the immunopositive neurons were measured using a computer image analyzer. We relatively divided the TG neurons into small $\left(<600 \mu \mathrm{m}^{2}\right)$, medium $\left(600 \sim 1200 \mu \mathrm{m}^{2}\right)$ and large neurons $(>1200$ $\left.\mu \mathrm{m}^{2}\right)$ by their cross-sectional areas.

\section{Behavioral test}

To estimate orofacial thermal hyperalgesia, rats were placed in a customized cylinder-type acrylic rodent restrainer $(6 \times 6 \times 12 \mathrm{~cm})$. Those cages had a forward hole so that a head could receive the heat stimulation and give a head withdrawal response. The test was carried out in a quiet darkroom and the animals were habituated to the environment at least $30 \mathrm{~min}$ prior to the start of the experiment. After laser heat stimulation was applied to the vibrissal pad, pain behavior was determined by the head withdrawal latency [21]. We used an infrared laser thermal stimulator (Infrared Diode Laser, LVI-810-30; LVI tech, Seoul, Korea) for the heat stimulation. The power of the thermal stimulator was adjusted to $5 \mathrm{~W}$ and current to 12.1 A. This heat intensity developed stable headwithdrawal latencies of approximately $12 \mathrm{sec}$ through the vibrissal pad at a distance of $10 \mathrm{~cm}$ from the laser source. Each rat received the thermal test twice at $5 \mathrm{~min}$ intervals. In this experiment, a cutoff time of $15 \mathrm{sec}$ was used to prevent possible tissue damage in heat exposure-vibrissal pad.

\section{Statistical analysis}

All experiments were performed at least three times. Data are expressed as mean \pm SD or mean \pm SE. The Student's $t$-test was used to determine the significances between two mean values, and $\mathrm{p}<$ 0.05 was considered statistically significant.

\section{RESULTS}

\section{Pain hypersensitivity in CFA-injected rats}

Previous studies have reported that CFA-mediated peripheral inflammation induces pain hyperalgesia and behavioral hypersensitivity $[22,23]$. We confirmed the pain hypersensitivity with thermal behavioral test following CFA-induced inflammation in rat orofacial regions. After CFA injection in rat vibrissal pad, the thermal pain hyperalgesia was observed in a time-dependent manner. CFA-injected rats showed significantly increased pain response to the thermal stimuli compared to the control rats (Fig. 1). The head withdrawal latency decreased dramatically $1 \sim 4$ days after CFA injection. This decrease was maintained for 10 days, gradually recovering to the control level by post-injection day 14. Vehicle-injected rats did not respond to heat stimulation, and there was no difference in thermal pain behavior between vehicle- 


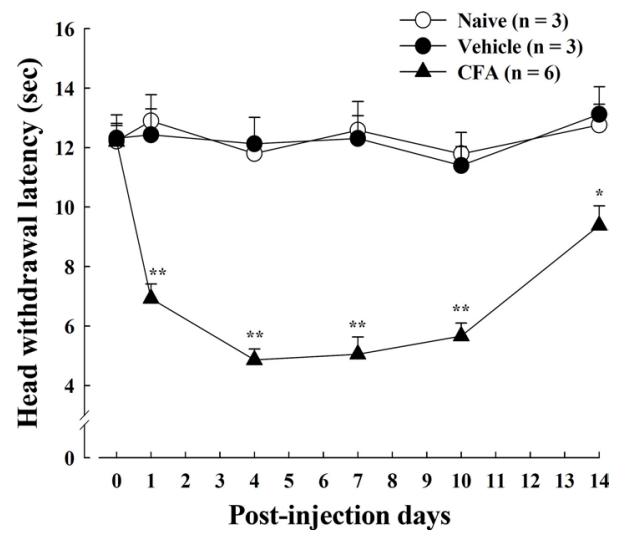

Fig. 1. Thermal hypersensitivity in CFA-induced inflammatory pain. Thermal pain hyperalgesia was observed at various time points after CFA injection into rat vibrissal pad. CFA-injected rats show significantly reduced head withdrawal latency time to heat stimulation compared to the vehicle-injected and naïve rats. Data is expressed as means \pm SE. Asterisks indicate a statistically significant difference between CFA and vehicle. ${ }^{*} \mathrm{p}<0.05,{ }^{* *} \mathrm{p}<0.001$ (Student's $t$-test). treated and naïve rats.

\section{Induction of ER stress in CFA-injected rat TG}

To investigate the connection between CFA-mediated inflammatory pain and ER stress response in TG, we determined the expression level of ER stress marker proteins at post-injection day 5 showing the maximum pain hyperalgesia. GRP78 is a chaperon protein that plays a critical role in cellular response to ER stress. The expression level of GRP78 in TG was determined by Western blot analysis at 5 days after CFA injection. As shown in Fig. 2A, GRP78 was significantly increased in the CFA-injected rat TG, but not control rats. Phosphorylation of eIF2a, another hallmark of ER stress response, results in attenuation of protein synthesis to prevent the accumulation of abnormal proteins. The p-eIF2 $\alpha$ was also significantly increased in the CFA-injected rat TG at 5 days (Fig. 2A). However, such an enhancement of ER stress response gene expression was not observed in the axon

A
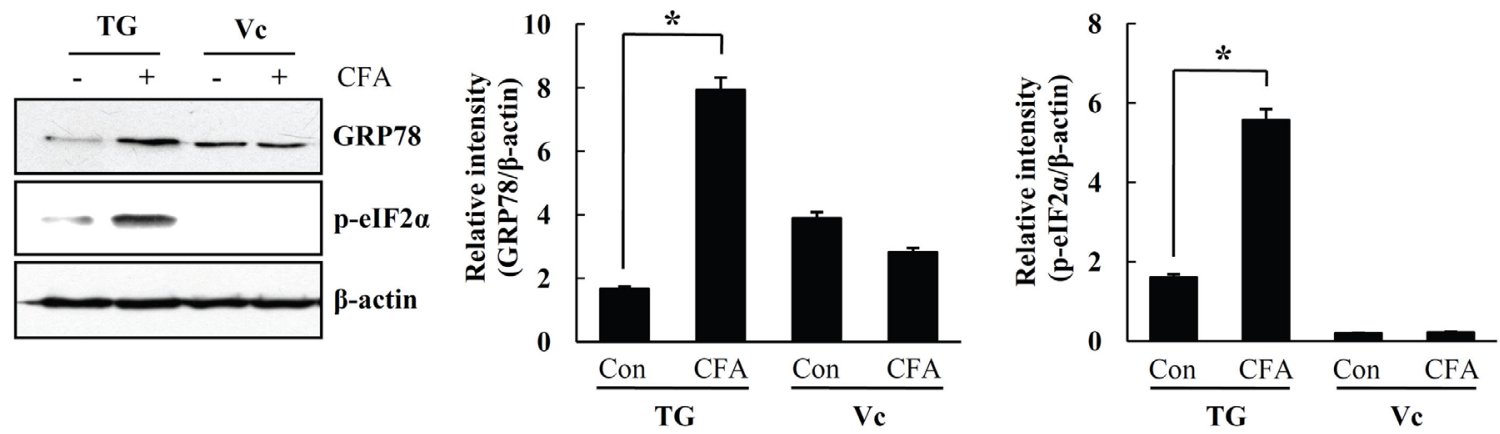

B

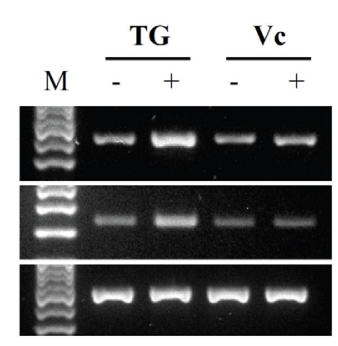

CFA
GRP78
ATF4
GAPDH
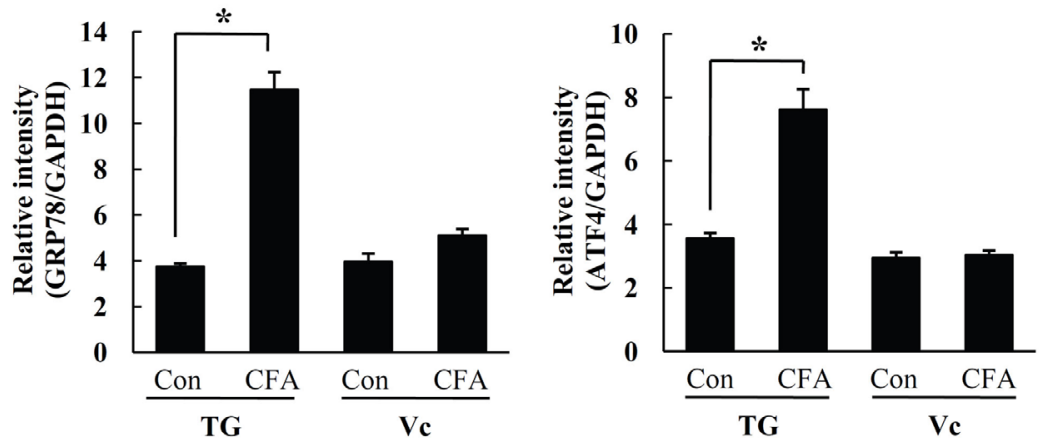

Fig. 2. The levels of ER stress-related proteins and mRNAs in CFA-injected rats. Rat TG and Vc of the brainstem were isolated from CFA-injected and control rats. (A) Equal amounts of cell lysates $(50 \mu \mathrm{g})$ were subjected to electrophoresis and analyzed by Western blot for GRP78 and p-eIF2 $\alpha$. At fifth day after CFA-injection, GRP78 and p-eIF2 $\alpha$ protein levels increased only in TG. Quantification of GRP78 and p-eIF2 $\alpha$ based on relative intensity and $\beta$-actin normalization (right). (B) Transcription levels of GRP78 and ATF4 mRNA were analyzed by RT-PCR using specific primers. The mRNA levels of GRP78 and ATF4 increased significantly in CFA-injected TG than control TG. GAPDH served as an internal loading control, and quantification of GRP78 and ATF4 was expressed as fold changes compared with levels in control TG (right). Data is expressed as means \pm SD of three independent experiments. ${ }^{*} \mathrm{p}<0.05$ (Student's $t$-test). TG, trigeminal ganglion; $\mathrm{Vc}$, trigeminal caudal nuclei. 
A

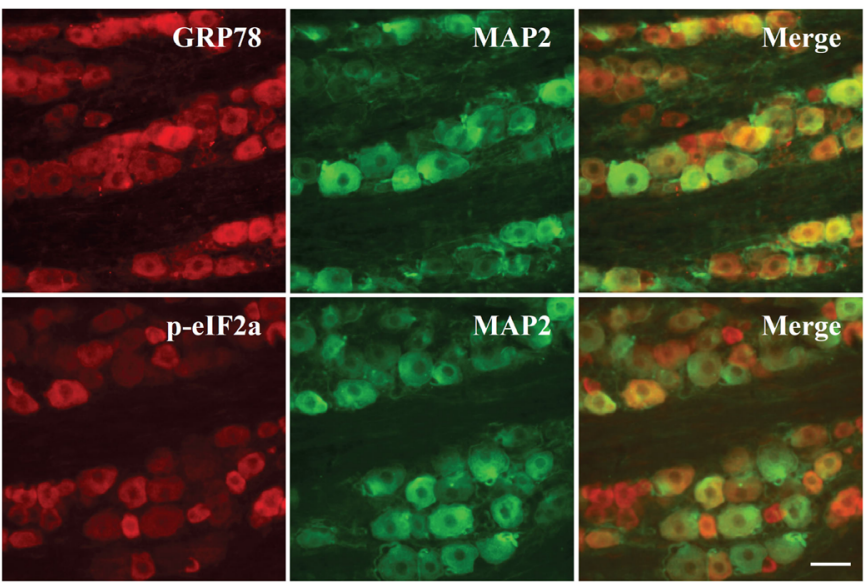

\section{B. GRP78}
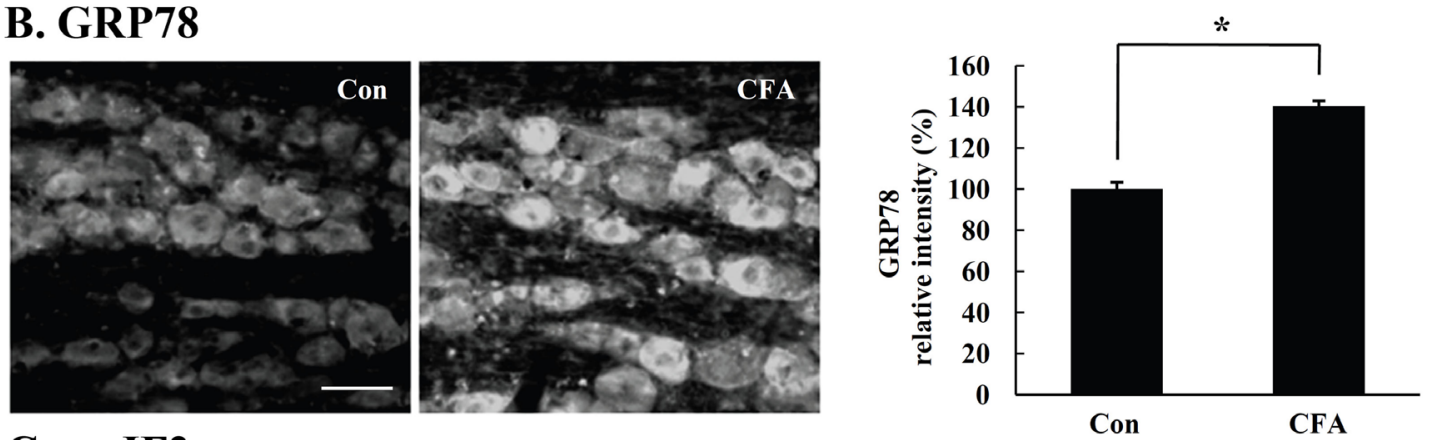

\section{C. p-eIF2a}
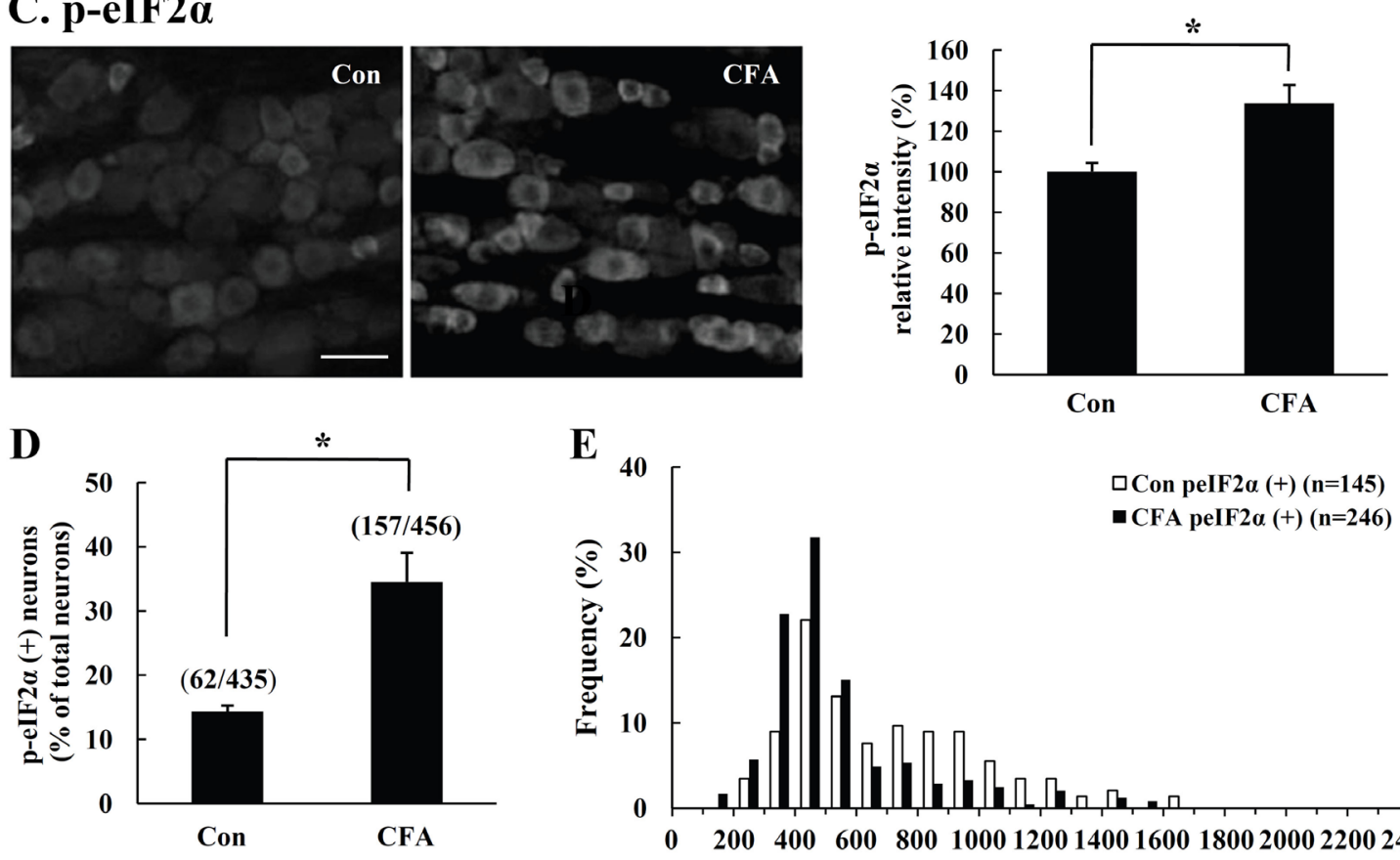

$\mathbf{E}$

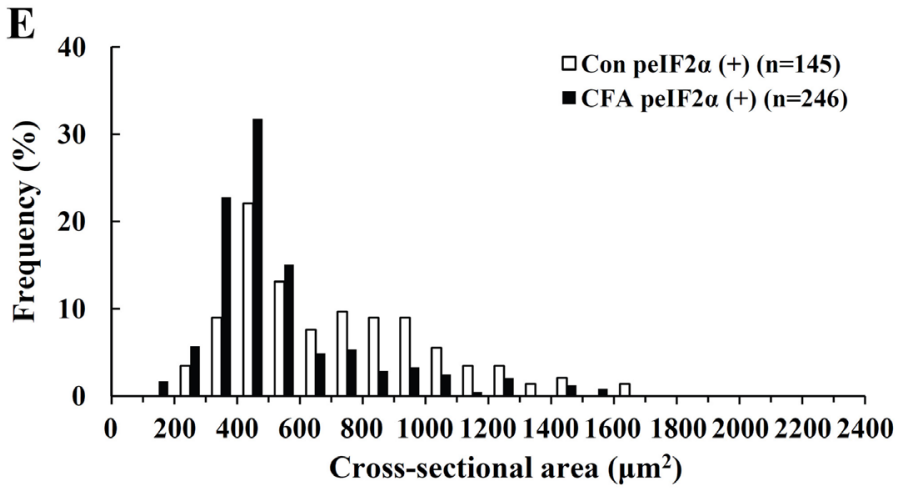

Fig. 3. Immunofluorescence analysis of GRP78 and p-eIF2 $\alpha$ in CFA-injected rat TG. On the fifth day after CFA-injection in rat vibrissal pad, we examined the expression of ER stress marker proteins in rat TG. (A) In control rats, GRP78 and p-eIF2a were mostly expressed in TG neurons, as demonstrated by colocalization of GRP78 or p-eIF2 $\alpha$ (red) and neuronal marker MAP2 (green). (B-C) GRP78 or p-eIF2a immunoreactivity increased remarkably in CFA-injected TG compared to the control TG. Quantification of the GRP78 or p-eIF2a immunopositive intensity increased in CFAinjected TG compared to control TG (right). (D) A significant increase in the number of p-eIF2a immunopositive neurons was observed in the CFAinjected TG. (E) The expression of p-eIF2a increased significantly in small and medium sized neurons after CFA-induced peripheral inflammation. Data is expressed as means \pm SD of three independent experiments. Scale bar $=50 \mu \mathrm{m} .{ }^{*} \mathrm{p}<0.05$ (Student's $t$-test). 
terminals in trigeminal caudal nuclei $(\mathrm{Vc})$ of the brainstems. We next investigated the effect of CFA-induced inflammation on transcriptional levels of ER stress-related genes in the rat TG by using RT-PCR analysis. As shown in Fig. 2B, GRP78 mRNA significantly increased in the CFA-injected rat TG, similarly to the protein expression level. ATF4, translated during the eIF2 $a$ mediated inhibition of protein synthesis, is also important in ER stress response. RT-PCR analysis showed a significant increase of ATF4 mRNA in the CFA-injected rat TG compared with control TG (Fig. 2B).

\section{Immunofluorescence analysis of ER stress markers in CFA- injected rat TG}

The immunoreactivities for ER stress marker proteins, GRP78 and p-eIF2 $\alpha$, were assessed by immunofluorescence analysis following CFA-mediated inflammation in rat TG. In control rats, GRP78 and p-eIF2 $\alpha$ expression was colocalized with neuronal marker MAP2, indicating that the ER stress proteins are mostly expressed in TG neurons (Fig. 3A). A significant increase of GRP78 and p-eIF2 $\alpha$ immunostaining was clearly observed in CFA-injected rat TG at 5 days compared with control TG (Fig. 3B E). Interestingly, we observed an increase of GRP78 expression in all neuron of the TG after CFA stimulation (Fig. 3B). In case of p-eIF $2 \alpha$, the expression was mainly augmented in small and medium-sized neurons (Fig. 3C). Peripheral inflammation induced a significant increase in the number of p-eIF $2 \alpha$ immunopositive neurons observed in the CFA-injected TG (Fig. 3D). Size measurements in CFA-injected rats revealed that ER

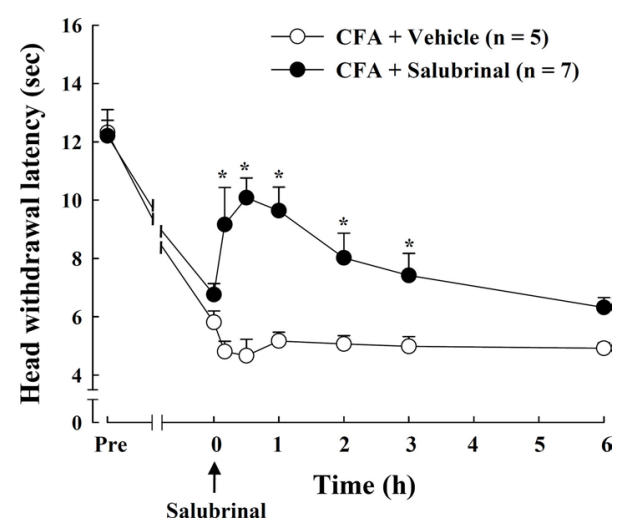

Fig. 4. Effect of salubrinal on thermal pain hypersensitivity produced by CFA injection. ER stress modulator salubrinal $(37.5 \mu \mathrm{M}, 10 \mu \mathrm{l})$ was administered into TG through cannula at 5 days after CFA injection (arrow). Salubrinal significantly inhibited CFA-induced thermal pain at $30 \mathrm{~min}$ after injection and the inhibitory effect was gradually reduced by $24 \mathrm{~h}$. Data is expressed as means \pm SE. Asterisks indicate a statistically significant difference between CFA-salubrinal vs. CFA-vehicle. ${ }^{*} \mathrm{p}<0.05$ (Student's $t$-test). stress response through p-eIF2 $\alpha$ signaling pathway specifically occurred in small and medium-sized neurons (Fig. 3E).

\section{Effect of salubrinal in CFA-induced pain hypersensitivity}

To determine the effect of ER stress in TG on the inflammatory pain behavior, we used ER stress modulator salubrinal. Thermal test was conducted to measure the pain behavioral response after salubrinal administration through a cannula in TG at 5 days after CFA injection. The CFA-induced heat hyperalgesia was significantly attenuated by salubrinal injection (Fig. 4). The pain inhibitory effect of salubrinal peaked $30 \mathrm{~min}$ after injection and gradually diminished over $24 \mathrm{~h}$. These results indicate that ER stress response plays an important role in CFA-induced pain behavior.

\section{DISCUSSION}

In this study, we demonstrated that the expression of ER stressrelated genes, GRP78, p-eIF2 $\alpha$ and ATF4, increased significantly in the TG neurons along with thermal hypersensitivity following CFA-induced inflammation in the rat vibrissal pad. The increase of thermal hyperalgesia was attenuated by the application of salubrinal, ER stress modulator, directly into the TG. This suggests that ER stress response is induced in the primary sensory neurons following orofacial inflammation, which is closely related to inflammatory pain.

ER stress response is a kind of protective mechanism for cell survival against various stresses such as glucose deprivation, $\mathrm{Ca}^{2+}$ depletion, oxidative stress and viral infection [3,24]. Until now, many studies related to ER stress have been conducted in various fields. In non-neuronal tissues, induction of ER stress genes due to obesity leads to the insulin resistance, induction of ER stress by transaortic constriction causes heart disease, and ER stressmediated cell death through PERK/p-eIF2a pathway results in ischemia/reperfusion injury [25-27]. Furthermore, lung cell death through ER stress induced lung inflammation following treatment with TRPV1 agonist in bronchial epithelial and alveolar cells, and activation of the ER stress signaling pathway IRE1/XBP1 regulated the innate immune signaling $[28,29]$. ER stress also regulated the iron homeostasis through hepcidin expression in liver as well as the chemotherapeutic effect through ATF4 dependent-autophagy [30,31]. In CNS neurons, ER stress-induced cell dysfunction has been suggested as a cause of the neurodegenerative disease like Alzheimer's disease and Parkinson's disease [32,33]. Activation of ER stress response increased the learning, memory and synaptic plasticity by induction of ER stress gene transcription [34]. Recently, induction of ER stress response in the primary 
sensory neurons was studied. Increase of GRP78 expression in DRG following painful facet joint injury and activation of ATF4 by painful facet joint distraction indicate that ER stress may play an important role as a modulator of painful injuries [35]. ER stress can also regulate the cell fate in primary sensory neurons following spinal cord injury [17]. Accumulation of abnormal proteins by $\mathrm{Ca}^{2+}$ depletion following nerve injury indicates that $\mathrm{ER}$ stress is related to the regulation of $\mathrm{Ca}^{2+}$ homeostasis in primary sensory neurons [36]. However, there is no information whether ER stress response occurs in TG neurons following pain-related peripheral inflammation and what is the role of the ER stress response in orofacial regions associated with painful injury. Herein we firstly observed the activation of ER stress response in the TG neurons following CFA-induced orofacial inflammation, and that the thermal hypersensitivity was attenuated by the application of ER stress modulator into the TG. This supports that ER stress response is closely related with painful inflammatory injuries in orofacial regions.

Interestingly, our results indicate that expression of GRP78 increased in all sized TG neuron, while $\mathrm{p}$-eIF2 $\alpha$ expression increased mainly in small and medium sized neurons after CFA-induced inflammation. This implies that certain neurons are specifically responsible for pain signaling in cooperation with ER stress response. Generally, pain pathway is activated differently depending on primary afferent nerve types [37]. Medium-diameter myelinated $(\mathrm{A} \delta$ ) fibers mediate acute, sharp and fast pain. These myelinated afferents differ considerably from the large-diameter myelinated $(\mathrm{A} \beta)$ fibers that respond to innocuous mechanical stimuli such as touch, sound and pressure. Small-diameter unmyelinated fibers mediate dull, dispersed and slow pain. Furthermore, ER stress response is activated through three different cascades initiated by three ER-localized protein sensors: IRE1a (inositol-requiring la), PERK (doublestranded RNA-dependent protein kinase (PKR)-like ER kinase) and ATF6 (activating transcription factor 6) [38]. Activation of ER stress response increased the expression of GRP78 protein, which activates the three cascades of ER stress response that enhance protein folding, maintain homeostasis and attenuate the translation. Thus, we speculate that ER stress response in the orofacial inflammatory pain may occur with different mechanisms in different TG primary sensory neurons. In other words, GRP78 and p-eIF $2 a$ signaling pathway is activated in small and medium sized TG neurons, but GRP78 and other signaling pathways may be activated in large sized TG neurons.

In peripheral sensory nerve system, the fibers sense stimuli from the periphery and convey the information to the central nervous system in the spinal cord [37]. As the ER stress response in TG neurons can affect the axon terminals $\left(\mathrm{Vc}_{\mathrm{c}}\right)$ in the brainstem, we evaluated the expression of ER stress-relative genes in Vc. But, we could not detect any change in ER stress-related gene expression in the $V_{c}$ regions after CFA inflammation. These differences between TG and Vc regions might be due to time points at which the experiment was conducted. Further study at various time points is needed to clarify the effect of inflammation on the ER stress response at the axon terminals.

Under ER stress condition, phosphorylation of the translation initiation factor eIF2 $\alpha$ reduces the protein translation to maintain the homeostasis [3]. In this study, we found that ER stress response was activated through the increase of the GRP78 and p-eIF2 $\alpha$ in CFA-induced orofacial pain model. Thus, it is speculated that translational attenuation of the analgesic mediators through ER stress response may play an important role in orofacial inflammatory pain.

Taken together, our results show that ER stress response is activated in TG following CFA-induced inflammation in rat vibrissal pad. This suggests that ER stress response may be involved in the regulation of inflammatory pain and play an important role in orofacial pain caused by peripheral inflammation.

\section{ACKNOWLEDGEMENTS}

This research was supported by the National Research Foundation of Korea (NRF) grant funded by the Korea government (MSIP) (to E.S.Y., 2012R1A1A3007549; to Y.S.K., 2009-0074967).

\section{REFERENCES}

1. Schröder M, Kaufman RJ (2005) ER stress and the unfolded protein response. Mutat Res 569:29-63.

2. Kaufman RJ (1999) Stress signaling from the lumen of the endoplasmic reticulum: coordination of gene transcriptional and translational controls. Genes Dev 13:1211-1233.

3. Xu C, Bailly-Maitre B, Reed JC (2005) Endoplasmic reticulum stress: cell life and death decisions. J Clin Invest 115:26562664.

4. Kaufman RJ (2002) Orchestrating the unfolded protein response in health and disease. J Clin Invest 110:1389-1398.

5. Shen X, Zhang K, Kaufman RJ (2004) The unfolded protein response--a stress signaling pathway of the endoplasmic reticulum. J Chem Neuroanat 28:79-92.

6. Hotamisligil GS (2006) Inflammation and metabolic disorders. Nature 444:860-867.

7. Hotamisligil GS (2010) Endoplasmic reticulum stress and the 
inflammatory basis of metabolic disease. Cell 140:900-917.

8. Nakajima S, Kitamura M (2013) Bidirectional regulation of NF-kappaB by reactive oxygen species: a role of unfolded protein response. Free Radic Biol Med 65:162-174.

9. Hu P, Han Z, Couvillon AD, Kaufman RJ, Exton JH (2006) Autocrine tumor necrosis factor alpha links endoplasmic reticulum stress to the membrane death receptor pathway through IRElalpha-mediated NF-kappaB activation and down-regulation of TRAF2 expression. Mol Cell Biol 26:3071-3084.

10. Gotoh T, Endo M, Oike Y (2011) Endoplasmic reticulum stress-related inflammation and cardiovascular diseases. Int J Inflam 2011:259462.

11. Deslauriers AM, Afkhami-Goli A, Paul AM, Bhat RK, Acharjee S, Ellestad KK, Noorbakhsh F, Michalak M, Power C (2011) Neuroinflammation and endoplasmic reticulum stress are coregulated by crocin to prevent demyelination and neurodegeneration. J Immunol 187:4788-4799.

12. Woolf CJ, Ma Q (2007) Nociceptors--noxious stimulus detectors. Neuron 55:353-364.

13. Dray A, Bevan S (1993) Inflammation and hyperalgesia: highlighting the team effort. Trends Pharmacol Sci 14:287290.

14. Sommer C, Kress M (2004) Recent findings on how proinflammatory cytokines cause pain: peripheral mechanisms in inflammatory and neuropathic hyperalgesia. Neurosci Lett 361:184-187.

15. Cunha FQ, Poole S, Lorenzetti BB, Ferreira SH (1992) The pivotal role of tumour necrosis factor alpha in the development of inflammatory hyperalgesia. Br J Pharmacol 107:660-664.

16. Dong L, Odeleye AO, Jordan-Sciutto KL, Winkelstein BA (2008) Painful facet joint injury induces neuronal stress activation in the DRG: implications for cellular mechanisms of pain. Neurosci Lett 443:90-94.

17. Ohri SS, Maddie MA, Zhao Y, Qiu MS, Hetman M, Whittemore SR (2011) Attenuating the endoplasmic reticulum stress response improves functional recovery after spinal cord injury. Glia 59:1489-1502.

18. Penas C, Guzmán MS, Verdú E, Forés J, Navarro X, Casas C (2007) Spinal cord injury induces endoplasmic reticulum stress with different cell-type dependent response. J Neurochem 102:1242-1255.

19. Fried K, Bongenhielm U, Boissonade FM, Robinson PP (2001) Nerve injury-induced pain in the trigeminal system. Neuroscientist 7:155-165.

20. Vit JP, Ohara PT, Sundberg C, Rubi B, Maechler P, Liu
C, Puntel M, Lowenstein P, Castro M, Jasmin L (2009) Adenovector GAD65 gene delivery into the rat trigeminal ganglion produces orofacial analgesia. Mol Pain 5:42.

21. Park CK, Kim K, Jung SJ, Kim MJ, Ahn DK, Hong SD, Kim JS, Oh SB (2009) Molecular mechanism for local anesthetic action of eugenol in the rat trigeminal system. Pain 144:8494.

22. Raghavendra V, Tanga FY, DeLeo JA (2004) Complete Freunds adjuvant-induced peripheral inflammation evokes glial activation and proinflammatory cytokine expression in the CNS. Eur J Neurosci 20:467-473.

23. Takeda M, Tanimoto T, Kadoi J, Nasu M, Takahashi M, Kitagawa J, Matsumoto S (2007) Enhanced excitability of nociceptive trigeminal ganglion neurons by satellite glial cytokine following peripheral inflammation. Pain 129:155166.

24. Schröder M, Kaufman RJ (2005) The mammalian unfolded protein response. Annu Rev Biochem 74:739-789.

25. Ozcan U, Cao Q, Yilmaz E, Lee AH, Iwakoshi NN, Ozdelen E, Tuncman G, Görgün C, Glimcher LH, Hotamisligil GS (2004) Endoplasmic reticulum stress links obesity, insulin action, and type 2 diabetes. Science 306:457-461.

26. Yamaguchi O, Higuchi Y, Hirotani S, Kashiwase K, Nakayama H, Hikoso S, Takeda T, Watanabe T, Asahi M, Taniike M, Matsumura Y, Tsujimoto I, Hongo K, Kusakari Y, Kurihara S, Nishida K, Ichijo H, Hori M, Otsu K (2003) Targeted deletion of apoptosis signal-regulating kinase 1 attenuates left ventricular remodeling. Proc Natl Acad Sci U S A 100:1588315888 .

27. Kumar R, Azam S, Sullivan JM, Owen C, Cavener DR, Zhang P, Ron D, Harding HP, Chen JJ, Han A, White BC, Krause GS, DeGracia DJ (2001) Brain ischemia and reperfusion activates the eukaryotic initiation factor 2alpha kinase, PERK. J Neurochem 77:1418-1421.

28. Thomas KC, Sabnis AS, Johansen ME, Lanza DL, Moos PJ, Yost GS, Reilly CA (2007) Transient receptor potential vanilloid 1 agonists cause endoplasmic reticulum stress and cell death in human lung cells. J Pharmacol Exp Ther 321:830-838.

29. Martinon F, Glimcher LH (2011) Regulation of innate immunity by signaling pathways emerging from the endoplasmic reticulum. Curr Opin Immunol 23:35-40.

30. Vecchi C, Montosi G, Pietrangelo A (2010) Huh-7: a human "hemochromatotic" cell line. Hepatology 51:654-659.

31. Rzymski T, Milani M, Singleton DC, Harris AL (2009) Role of ATF4 in regulation of autophagy and resistance to drugs and hypoxia. Cell Cycle 8:3838-3847. 
32. Katayama T, Imaizumi K, Sato N, Miyoshi K, Kudo T, Hitomi J, Morihara T, Yoneda T, Gomi F, Mori Y, Nakano Y, Takeda J, Tsuda T, Itoyama Y, Murayama O, Takashima A, St GeorgeHyslop P, Takeda M, Tohyama M (1999) Presenilin-1 mutations downregulate the signalling pathway of the unfolded-protein response. Nat Cell Biol 1:479-485.

33. Dawson TM, Dawson VL (2003) Rare genetic mutations shed light on the pathogenesis of Parkinson disease. J Clin Invest 111:145-151.

34. Costa-Mattioli M, Gobert D, Harding H, Herdy B, Azzi M, Bruno M, Bidinosti M, Ben Mamou C, Marcinkiewicz E, Yoshida M, Imataka H, Cuello AC, Seidah N, Sossin W, Lacaille JC, Ron D, Nader K, Sonenberg N (2005) Translational control of hippocampal synaptic plasticity and memory by the eIF2alpha kinase GCN2. Nature 436:11661173.
35. Dong L, Guarino BB, Jordan-Sciutto KL, Winkelstein BA (2011) Activating transcription factor 4, a mediator of the integrated stress response, is increased in the dorsal root ganglia following painful facet joint distraction. Neuroscience 193:377-386.

36. Rigaud M, Gemes G, Weyker PD, Cruikshank JM, Kawano T, Wu HE, Hogan QH (2009) Axotomy depletes intracellular calcium stores in primary sensory neurons. Anesthesiology 111:381-392.

37. Basbaum AI, Bautista DM, Scherrer G, Julius D (2009) Cellular and molecular mechanisms of pain. Cell 139:267284.

38. Ron D, Walter P (2007) Signal integration in the endoplasmic reticulum unfolded protein response. Nat Rev Mol Cell Biol 8:519-529. 